This manuscript was accepted and published by the Journal of Analytical and Applied Pyrolysis.

Publication data of the final, corrected work:

Várhegyi, G.; Szabó, P.; Mok W. S. L., Antal, M. J., Jr.: Kinetics of the thermal decomposition of cellulose in sealed vessels at elevated pressures. Effects of the presence of water on the reaction mechanism. J. Anal. Appl. Pyrolysis 1993, 26, 159-174. doi: $10.1016 / 0165-2370(93) 80064-7$

\title{
KINETICS OF THE THERMAL DECOMPOSITION OF CELLULOSE IN SEALED VESSELS AT ELEVATED PRESSURES. EFFECTS OF THE PRESENCE OF WATER ON THE REACTION MECHANISM.
}

\section{Gábor Várhegyi* and Piroska Szabó}

Hungarian Academy of Sciences, Research Laboratory for Inorganic Chemistry, P.O.Box 132, Budapest 1518, Hungary

\section{William Shu-Lai Mok and Michael Jerry Antal, Jr.}

Hawaii Natural Energy Institute and the Department of Mechanical Engineering, University of Hawaii at Manoa, Honolulu, Hawaii 96822

*Corresponding author. Email: varhegyi.gabor@t-online.hu or gvarhegyi@gmail.com

\begin{abstract}
The thermal decomposition of Avicel cellulose was studied by non-isothermal differential scanning calorimetry in hermetically sealed sample holders. The experimental results, which were published earlier, showed a marked catalytic effect of the water on the cellulose decomposition. Here we propose a reaction scheme containing two rate determining reactions to describe the result. The corresponding model resulted in a good fit between the experimental and the calculated data. The results indicate that the reaction starts with cellulose hydrolysis which may be followed immediately by decomposition reactions to intermediate products. The intermediates undergo further water catalyzed decomposition reactions giving char, water and gases. The results may help to understand biomass pyrolysis under experimental or industrial conditions where the thickness of the layer, the size of particles or the enclosure of the reactor keeps part of the water vapors formed during the reaction in the pores or between the particles of the decomposing material.
\end{abstract}




\section{INTRODUCTION}

The use of elevated pressures during biomass pyrolysis results in increased charcoal yield and reduced energy consumption $[1,2]$. The industrial prospects of this field were the principal reasons for carrying out the present study on the fundamental chemical processes taking place in the presence of the pyrolysis products at elevated pressures.

Cellulose is generally believed to decompose by the Broido - Shafizadeh mechanism [3, 4]:

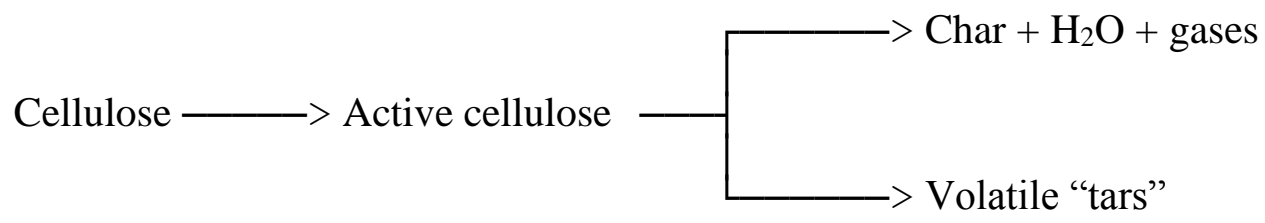

The experience of the present authors does not support this reaction scheme. The thermal decomposition of Avicel cellulose in thin layers $(\sim 0.1 \mathrm{~mm})$ at moderate heating rates with a considerable flow rate of an inert purge gas evidenced simple patterns which can be described by the assumption of a single rate determining reaction $[5,6]$. This rate determining reaction is probably the degradation of the cellulose to monomers and oligomers. The observed gases, vapors and chars may be due to the secondary reactions of the monomers and oligomers. When the transport of the volatile products from the sample layer is hindered, the decomposition mechanism becomes more complex and such phenomena arise which cannot be explained by the Broido Shafizadeh scheme. Mok and Antal [7] have shown that an increase of pressure decreases the endothermic reaction heat of cellulose decomposition. At a low flow rate of the inert purge gas the reaction turned exothermic at pressures higher than 0.5 $\mathrm{MPa}$ [7]. Várhegyi et al. [5] observed that the application of a closed sample holder with a pinhole at the top decreased the decomposition temperature and resulted in sharper DTG peaks in thermogravimetry - mass spectrometry experiments.Antal et al. [8] showed that the use of steam instead of an inert purge gas may decrease the decomposition temperature of cellulose in open sample holders. None of these observations can be explained by the Broido - Shafizadeh mechanism. To clarify the problems we studied charcoal formation from cellulose, hemicellulose and biomass plant materials in completely sealed sample holders by differential scanning calorimetry [9]. We found that higher sample loading increases the charcoal yield and lowers the reaction temperature. It was shown experimentally that the observed effects cannot be due to the self-heating during the exothermic decomposition. A systematic variation of the experimental conditions and addition of extra water to the sample proved that a major part of the observed effects are due to the catalytic influence of the water on the reaction. Since water is a major product of the decomposition, the overall process can be regarded to be an autocatalytic reaction. In the present study we shall deal with the reaction kinetic evaluation of the same experiments. Due to the complexity of the chemical reactions, the treatment is restricted to the cellulose experiments. We should like to underline, however, that essentially the same phenomena were observed in 
the experiments with cellulose, hemicellulose and whole biomass samples, hence the results may contribute to the better understanding of behavior the whole biomass samples, too.

\section{EXPERIMENTAL}

\section{Measurements}

A detailed description of the experimental work can be found in our previous paper [9]. Here only a brief summary is given. The measurements were carried out in a Setaram DSC 111 differential scanning calorimeter. Completely sealed high pressure sample holders were employed. To ensure chemical kinetic control of the decomposition, heat transfer problems were reduced by applying low heating rate $\left(5^{\circ} \mathrm{C} / \mathrm{min}\right)$ and relatively low amounts of cellulose $(5-23 \mathrm{mg})$. We found $5 \mathrm{mg}$ to be the least amount of cellulose permitted by the sensitivity of the apparatus in sealed high pressure sample holders. The pressure during the decomposition was estimated in separate experiments and was found to be between 3 and $15 \mathrm{MPa}$. High purity microcrystalline cellulose (Avicel PH105) was employed. The samples had already some moisture $(6.6 \%)$. To examine the effects of this moisture one experiment was executed using dry cellulose taken from a desiccator. Some of the experiments were carried out with the addition of 0.6 to $1.8 \mathrm{mg}$ water to the cellulose. In a few experiments $20 \%$ acetic acid solution or solid $\mathrm{CO}_{2}$ was added to the samples before the DSC run. Since no marked effects were observed, the $\mathrm{CO}_{2}$ and $\mathrm{CH}_{3} \mathrm{COOH}$ experiments were not used in the present work. The measurements used in the kinetic calculations are summarized in Table 1. They are divided into two groups. Group A contains the experiments measured at low amounts of cellulose (5 - 10 $\mathrm{mg}$ ). Group B contains the experiments of higher cellulose masses (14 - $22 \mathrm{mg}$ ) and two special experiments, B1 and B2, which were carried out in volumes reduced by stainless steel inserts. Experiments B1 and B2 served to show that the temperature and sharpness of the DSC peaks are determined by the ratio of the cellulose mass and the volume of the sample holder (and not by a self-heating phenomenon). The experiments in Group A are thought to be more reliable (less distorted by systematic experimental errors) than the ones listed in Group B. Special figures showing the systematic variation of the DSC peak characteristics with the mass loading and amount of initial water content can be found in our previous work [9]. The Figures of the present paper are aimed only to show the fit between the calculated and the measured data. 
TABLE 1. List of the Experiments.

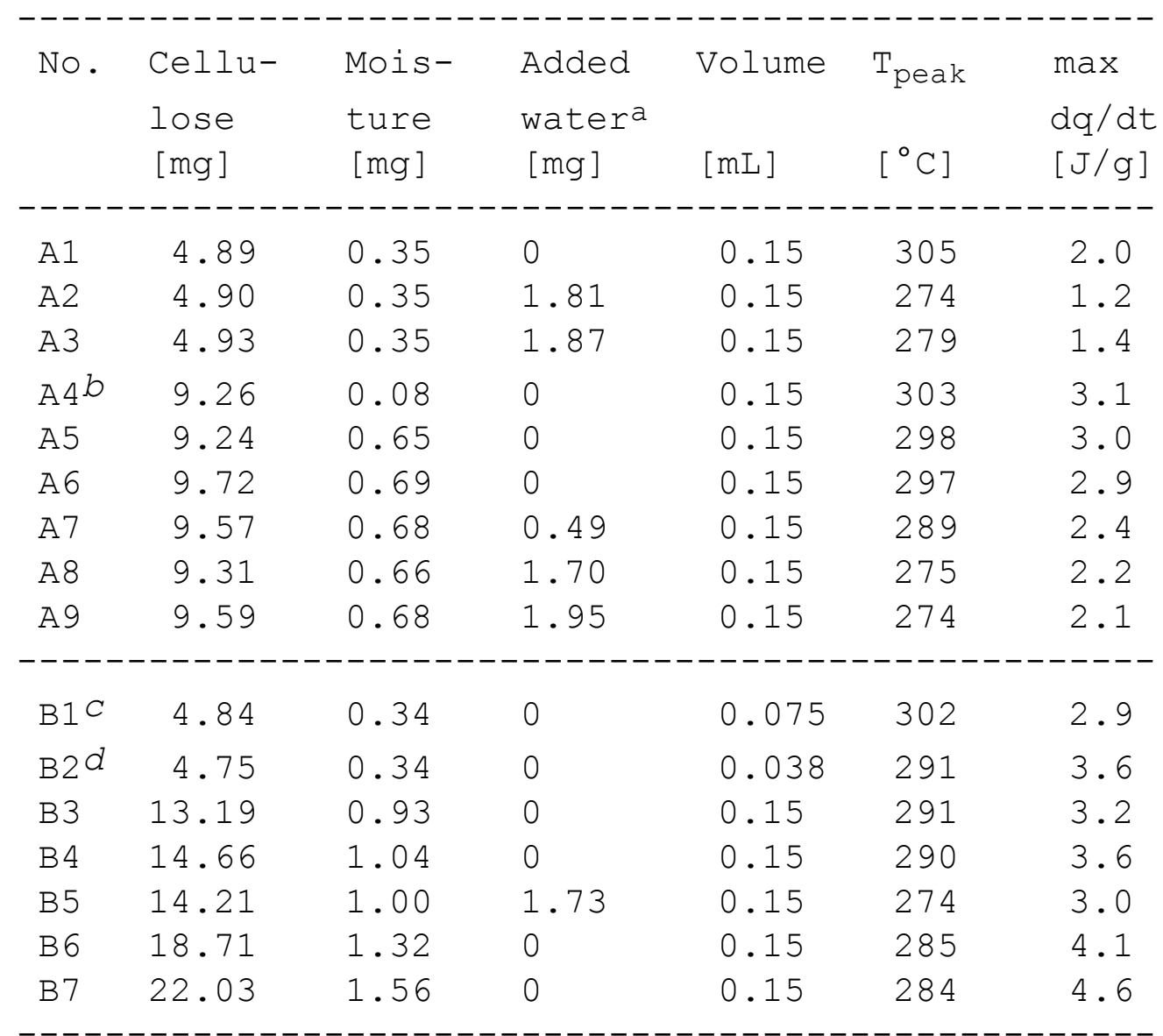

${ }^{a}$ The amount of extra water added to the samples before sealing the sample holders. ${ }^{\mathbf{b}}$ Experiment with dried cellulose. ${ }^{\mathbf{c}, \mathbf{d}}$ The dead volume of the sample holder was decreased by stainless steel inserts.

\section{Calculations}

The calculations were carried out by an "AT-486" type computer. The programs were written in FORTRAN and run under DOS. The method of least squares was applied with constraints described in the Results and Discussions. For each experiment a separate least squares sum was formed:

$S_{\mathrm{j}}=\sum_{\mathrm{i}}\left(\left[(\mathrm{d} q / \mathrm{d} t)_{\mathrm{i}}{ }^{\text {exper }}-(\mathrm{d} q / \mathrm{d} t)_{\mathrm{i}}{ }^{\mathrm{calc}}\right] /(\mathrm{d} q / \mathrm{d} t)_{\max }\right)^{2} / N_{\mathrm{j}}$

where $S_{\mathrm{j}}$ is the least squares sum of the $j$ th experiment, $(\mathrm{d} q / \mathrm{d} t)_{\mathrm{i}}{ }^{\text {exper }}$ and $(\mathrm{d} q / \mathrm{d} t)_{\mathrm{i}}{ }^{\text {calc }}$ represent the points of a base-line corrected DSC curve and points calculated from the kinetic model, respectively, in units W/g. The term $(\mathrm{d} q / \mathrm{d} t)_{\max }$ is the highest experimental $\mathrm{d} q / \mathrm{d} t$ value and $N_{\mathrm{j}}$ is the number of experimental points. (The division by $(\mathrm{d} q / \mathrm{d} t)_{\max }$ serves to normalize $S_{\mathrm{j}}$.) Groups of experiments were evaluated simultaneously and

$S=\sum_{\mathrm{j}} S_{\mathrm{j}} / m \quad(j=1,2, \ldots m)$

was minimized, where $m$ is the number of the experiments in the given group. The fit between the experimental and the calculated $\mathrm{d} q / \mathrm{d} t$ curves was characterized by a deviation expressed as percent: 
$D=100 S^{0.5}[\%]$

Unfortunately, the experimental errors associated with the measured data were neither random nor independent of each other. Hence the elegant techniques of mathematical statistics were not applicable in judging the quality of the fit or finding a "best" parameter set. We considered a "good fit" to exist when a visual inspection of the results revealed a good match between the temperatures, width, size and shape of the experimental and the calculated $\mathrm{d} q / \mathrm{d} t$ curves. This occurred at $D$ values below $5 \%$. We had to take into account the chemistry of the processes to make distinctions between the parameter sets resulting in good fits.

\section{RESULTS AND DISCUSSIONS}

\section{General considerations}

Hundreds of chemical reactions may occur in a closed sample holder. A workable model, however, can contain only a limited number of unknown parameters. Hence we must look for a simplified reaction scheme with a complexity commensurable with that of the Broido - Shafizadeh model. The DSC experiments in closed sample holders differ from our earlier TG-MS experiments in three crucial points:

(i) the volatile products cannot escape from the hot zone after their formation

(ii) the observed signal arises from both the primary and the secondary reactions

(iii) the volatile end-products of the reaction $\left(\mathrm{CO}, \mathrm{CO}_{2}, \mathrm{H}_{2} \mathrm{O}\right)$ accumulate in high concentration in the sample holder during the course of the decomposition. Note, that one of these products, $\mathrm{H}_{2} \mathrm{O}$ proved to have a strong catalytic effect on the decomposition [9].

Considering the above factors one might expect complex DSC curves with special features (local maxima or shoulders) corresponding to the various partial reactions. In reality, however, we observed simple DSC curves with a single peak followed by a low "tailing" section. These curves resembled those of the open pan TG-MS experiments. The tailing section may result from the slow charring of the solid residue and was excluded from the kinetic evaluation. The simple, regular shapes of the DSC peaks suggested the possibility of a relatively simple model. As a first attempt we tried to explain the observed phenomena by the assumption of a single rate determining water catalyzed reaction. This type of modelling, however, resulted in activation energies higher than the chemical bond energies and was rejected. Hence we had to assume at least two rate determining reactions.

There are different ways to interpret these two rate determining reactions. We can assume that one reaction determines the rate of the solid phase reaction and one describes the secondary reactions of the volatiles. Since water addition shifts the whole DTG curve to lower temperatures, water seems to be participate in both reactions. An alternative way is to assume solid phase intermediate products which 
decompose in the second reaction into volatile products. The mathematical equations are identical in both cases.

The non-catalyzed reaction, observed in the open pan TG experiments, has negligible reaction rate within the lower temperature interval of the sealed sample holder DSC experiments. Test calculations have shown, however, that the two DSC experiments with the lowest initial concentration of water, A1 and A4 (See Table 1), cannot be evaluated without taking into account the small amount of water produced by the non-catalyzed reaction. In this way the following model was obtained:

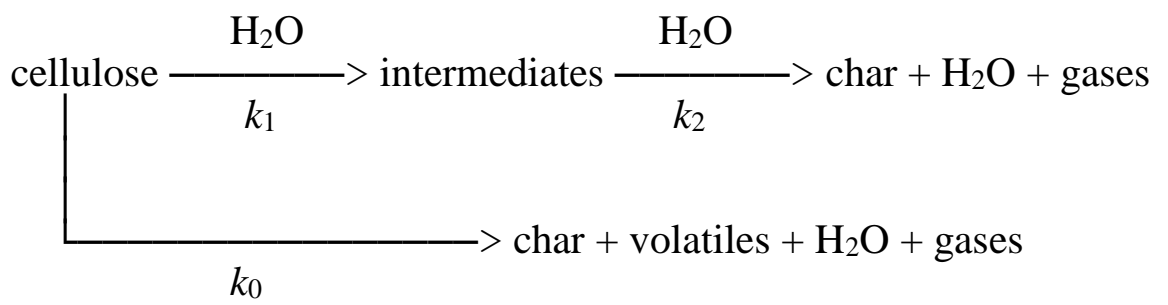

Here $k_{0}, k_{1}$ and $k_{2}$ are rate constants for reactions 0,1 , and 2, respectively. Reaction 0 is the noncatalyzed decomposition observed in the open pan TG experiments. Reaction 1 is the solid state reaction of cellulose in the presence of water. (Its chemistry will be discussed later.) Reaction 2 is the secondary reaction of the intermediates in the sealed sample holder. A similar reaction mechanism was proposed earlier by Mok and Antal [7]. At that time, however, the catalytic influence of the water vapor had not been recognized.

\section{Mathematical formulation}

The mathematical equations belonging to reaction scheme (5) are formulated as follows. Let $C, I$ and $W$ denote the amounts of cellulose, intermediates and water, respectively, divided by the initial cellulose mass. The concentration of water in the cellulose layer is assumed to be approximately proportional to the water vapor concentration in the gas phase, $\left[\mathrm{H}_{2} \mathrm{O}\right]$. In this way the rate of the cellulose consumption in reaction 1 is assumed to be proportional to $C$ and $\left[\mathrm{H}_{2} \mathrm{O}\right]$, while reaction 0 has first order kinetics:

$-\mathrm{d} C / \mathrm{d} t=k_{0} C+k_{1}\left[\mathrm{H}_{2} \mathrm{O}\right] C$

where $\left[\mathrm{H}_{2} \mathrm{O}\right]$ is expressed in $\mathrm{g} / \mathrm{mL}$. The intermediates are produced by reaction 1 and consumed by reaction 2. Denoting the yield of intermediates from a unit mass of cellulose by $Y_{\mathrm{I}}$, we get

$\mathrm{d} I / \mathrm{d} t=\mathrm{k}_{1} C Y_{\mathrm{I}}\left[\mathrm{H}_{2} \mathrm{O}\right]-\mathrm{k}_{2} I\left[\mathrm{H}_{2} \mathrm{O}\right]$

Let $Y_{0}$ and $Y_{1}$ be the yields of water formed from a unit mass of cellulose through reactions 0 and 1, respectively, and let $Y_{2}$ be the amount of water formed from a unit mass of intermediates in reaction 2. Then

$\mathrm{d} W / \mathrm{d} t=Y_{0} \mathrm{k}_{0} \mathrm{C}+Y_{1} \mathrm{k}_{1}\left[\mathrm{H}_{2} \mathrm{O}\right] C+Y_{2} k_{2} I\left[\mathrm{H}_{2} \mathrm{O}\right]$

The water concentration in the gas phase is approximated by 
$\left[\mathrm{H}_{2} \mathrm{O}\right]=m_{0} W / V$

where $m_{0}$ is the initial cellulose mass $(\mathrm{g})$ and $V$ is the internal volume of the sample holder (mL). We supposed here that the water is mainly in the vapor phase. The possibility of a separate liquid phase will be discussed later, in the paragraph dealing with the evaluation of Experiments B1 - B7. The initial conditions of equations (6) - (8) are

$C(0)=1, \quad I(0)=0 \quad$ and $\quad W(0)=W_{0}$

where $W_{0}$ is the sum of the moisture content of the sample and the amount of optional extra water divided by the initial cellulose mass. From the definition of $Y_{\mathrm{I}}$ and $Y_{1}$ follows

$Y_{\mathrm{I}}+Y_{1}=1$

Each rate constant is assumed to be an Arrhenius type expression:

$k_{\mathrm{i}}=A_{\mathrm{i}} \exp \left(-E_{\mathrm{i}} / R T\right), \quad i=0,1,2$.

Note that temperature $T$ is a linear function of time $t$. The heat of the overall reaction is composed from the heats of reactions 0,1 and 2 , hence

$\mathrm{d} q / \mathrm{d} t=H_{0} k_{0} C+H_{1} k_{1}\left[\mathrm{H}_{2} \mathrm{O}\right] C+H_{2} k_{2} I\left[\mathrm{H}_{2} \mathrm{O}\right]$

Here $q$ is the reaction enthalpy and $H_{0}, H_{1}$ and $H_{2}$ are the reaction heats of the partial reactions. For convenience, $q, H_{0}, H_{1}$ and $H_{2}$ are expressed in [J/g]. (Calculations with molar quantities would require additional assumptions.) Since cellulose decomposition is exothermic under the applied conditions [7,9], $\mathrm{d} q / \mathrm{d} t<0$.

\section{Additional relations}

Due to the great number of unknown parameters, we have to consider carefully, what other relations may exist. The parameters belonging to reaction 0 were taken from our previous work [5-7]: $E_{0}=233.8 \mathrm{~kJ} / \mathrm{mol}, \log A_{0}=17.60, Y_{0} \sim 0.20, H_{0} \sim 240 \mathrm{~J} / \mathrm{g}$. We have some information about the overall water yield, too. The combined yield of the reaction products evaporating at room temperature was measured after each experiment and was found to be $31 \pm 1 \%$. (Here the percent refers to the dry cellulose content of the sample and the quantity after the $\pm \operatorname{sign}$ is the standard deviation.) Hence the overall water yield should be a value between 0 and $\sim 0.31$. Since only a very small portion of the cellulose decomposes through reaction 0 under our experimental conditions, we can approximate the overall water yield as $Y_{1}+Y_{\mathrm{I}} Y_{2}$ and use the following inequality as an approximation:

$Y_{1}+Y_{\mathrm{I}} Y_{2} \leq 0.31$ 
Unfortunately, the experimental method we applied in the present work did not allow the exact determination of the amount of water produced.

Finally, we should consider what magnitudes of activation energies are acceptable in our case. In our former studies, the activation energy of the non-catalytic cellulose decomposition was scattered around $230 \mathrm{~kJ} / \mathrm{mol}$. It is a plausible assumption that the catalytic effects lower the activation energies, or at least, the activation energies are not higher than in the case of the non-catalyzed reactions. Hence we obtain

$E_{1} \leq 230 \mathrm{~kJ} / \mathrm{mol}$ and $E_{2} \leq 230 \mathrm{~kJ} / \mathrm{mol}$

These relations are intended to hinder a convergence to meaningless $E_{1}$ and $E_{2}$ values during the evaluation of the data. The upper limit, $230 \mathrm{~kJ} / \mathrm{mol}$, was chosen only as a very rough approximation. Fortunately, the results are not sensitive to the exact choice of this limit. All of the calculations have been repeated with an arbitrarily chosen lower value, assuming $E_{1} \leq 200$ and $E_{2} \leq 200$. The corresponding results are indicated in Tables 2 and 3, at the end of this document, as "test runs". A few evaluations were carried out with values higher than $230 \mathrm{~kJ} / \mathrm{mol}$, too. All of these calculations, however, resulted in the same signs and similar magnitudes of the parameters as the application of (15).

\section{Evaluation of experiments A1 - A9}

The practice of thermal analysis shows that the information content of a single thermoanalytical peak is usually not enough for the determination of more than four independent unknown parameters. One of the unknown parameters is connected with the peak area while the other three may be reaction kinetic parameters. (For a detailed review on this field see e.g. reference [10]). In our case we have eight unknown parameters: $A_{1}, A_{2}, E_{1}, E_{2}, Y_{1}, Y_{2}$ and $H_{1}, H_{2}$. Hence the independent, one-by-one evaluation of the experiments is an ill-defined problem. Calculations of this type resulted in highly scattered values of the parameters. Though the signs and the magnitudes of the parameters revealed some useful information, the authors judged these results as not suitable for publication.

In other calculations we searched for a single parameter set describing the nine experiments simultaneously. These calculations resulted in bad fits which may be due to the fact that our case is different from the classical reasoning used in the deduction of the method of least squares from the principle of the maximum likelihood. As it has been mentioned already, the errors of points $(\mathrm{d} q / \mathrm{d} t)_{\mathrm{i}}{ }^{\text {exper }}$ in sum (2) are not independent random errors. In modern thermal analysis, the random components of the errors are filtered out almost completely by the hardware of the apparatus and by the computerized data acquisition. The main components of the experimental errors are systematic and may vary from experiment to experiment [10]. Since a single parameter set failed to describe nine experiments, we looked for parameter sets very close to each other. To achieve this, the nine experiments of group A were evaluated simultaneously. Each experiment had its own parameter set. The parameters of each experiment were varied independently of 
each other during the minimization. To force the parameters close to each other, a "penalty" was added to the least squares sum:

penalty $=\sum_{\mathrm{n}} \sum_{\mathrm{j}} \mu_{\mathrm{n}}^{2}\left[(\text { parameter })_{\mathrm{n}, \mathrm{j}}-(\text { average parameter })_{\mathrm{n}}\right]^{2}$

where $(\text { parameter })_{\mathrm{n}, \mathrm{j}}$ represents the $n$th parameter of the $j$ th experiment. The term (average parameter $)_{\mathrm{n}}$ stands for the average calculated from the values of the $n$th parameters. The parameters were obtained through the minimization of $S+$ penalty, where $S$ is the least squares sum defined by (2) and (3). The average parameters were recalculated at each function evaluation during the numerical minimization. Coefficients $\mu_{\mathrm{n}}$ serve to control the scattering of the parameters. Their values were chosen in such a way, that the different type of parameters $(E, \log A, Y$ and $H)$ would be normalized to roughly the same magnitude in (16). Test calculations have revealed that increasing all of the $\mu_{\mathrm{n}}$ values by the same factor forced the parameter sets of the different experiments closer and closer to each other on the expense of a slight worsening of the fit between the experimental and the calculated data. At high values of $\mu_{\mathrm{n}}$, however, bad fits were obtained. As a compromise, the $\mu$ values for parameters $\log A_{\mathrm{i}}, E_{\mathrm{i}}, Y_{\mathrm{i}}$ and $H_{\mathrm{i}}$ were chosen as 0.1 , $0.01,1$ and 0.01 , respectively. The averages and deviations of the parameters obtained in this way are shown in Table 2, at the end of this document. The assumptions indicated in the first column will be described later. The fact that the calculated kinetic parameters evidence low scatter shows that the experiments with different cellulose mass, moisture and amount of extra water can be described by the same chemical assumptions and almost identical parameters.

\section{Cellulose hydrolysis as the first reaction step}

The calculations resulted in a water yield for the first reaction of $Y_{1} \sim-0.28$. The conversion of this value into a molar quantity yields the consumption of 2.5 water molecules by each glucose unit of the cellulose. In the case of a regular cellulose hydrolysis process, one water molecule is absorbed by each glucose unit, which corresponds to

$Y_{1}=-0.111$

A recent study on cellulose hydrolysis at temperatures above $200^{\circ} \mathrm{C}$ supplied evidence for other type of cellulose hydrolysis reactions which do not yield sugars, but no details are known about these reactions [11]. From a chemical point of view it is hard to imagine reactions with $Y_{1} \sim-0.28$. It is more probable that the results indicate the mathematically ill-defined nature of $Y_{1}$ in the model. To clarify this problem, we repeated the calculations by adding assumption (17) to the model. As the corresponding data of Table 2 show, deviations $D$ [characterizing the fit by equations (2)-(4)] are slightly worse than in the previous case. However, a visual observation of the experimental and the calculated $\mathrm{d} q / \mathrm{d} t$ curves reveals that these 
calculations still result in good fit. (See Figure 1.) Therefore the $Y_{1}=-0.28$ result of the free minimization is not considered significant.

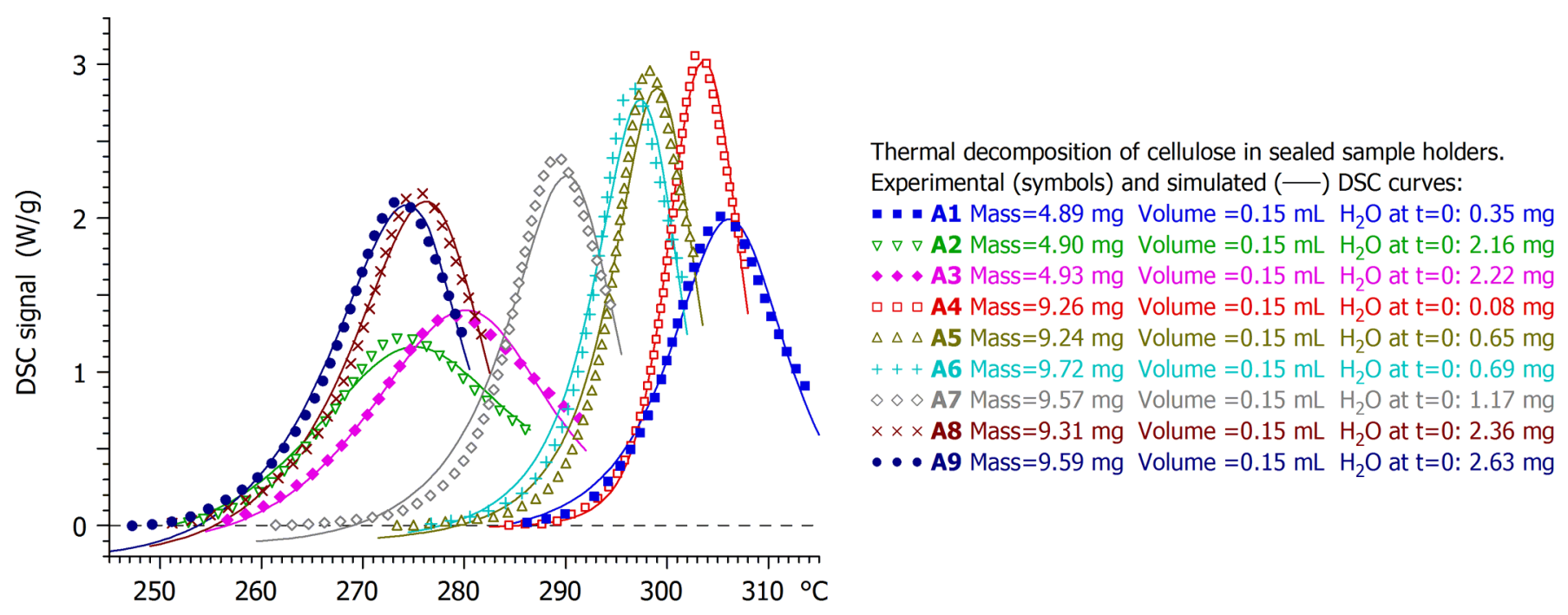

Figure 1: Evaluation of experiments A1 - A9 assuming one mol / monomer unit water uptake in reaction 1 $\left(Y_{1}=-0.111\right)$. The parameter sets of the different experiments were forced to be close to each other by constraint (16). The symbols represent the points of experiments, as marked in the text field. The curves drawn by solid lines are the corresponding calculated $\mathrm{d} q / \mathrm{d} t$ curves. The total $\mathrm{H}_{2} \mathrm{O}$ of the experiments (moisture + added water) is also indicated.

There is a further question, however: is the first reaction really a hydrolysis process or can the experiments be described with non-negative $Y_{1}$ values, too? To get an answer, we carried out the calculations with the hypothesis

$Y_{1}=0$

In that case the fit between the experimental and the calculated data was considerably worse. Deviation $D$ was higher than $5 \%$ for 5 of the 9 experiments and a visual inspection of the fit revealed that the theoretical $\mathrm{d} q / \mathrm{d} t$ functions were unable to describe the sharp peak tops of the experimental curves. Hence assumption (18) was considered less probable than assumption (17). Though the exact value of $Y_{1}$ could not be determined, reaction 1 seems to be cellulose hydrolysis. Lacking any further information about $Y_{1}$, we accept the plausible assumption of $Y_{1}=-0.111$.

The heat of the first reaction

As the $H_{1}$ values of Table 2 show, the first reaction is markedly endothermic. We tested the significance of the endothermic reaction heat obtained by the model by carrying out test calculations with the hypothesis

$H_{1}=0$ 
The fit was worse than in any other case and $Y_{1}$ converged to a value corresponding to the consumption of about nine $\mathrm{H}_{2} \mathrm{O}$ per one glucose unit of the cellulose. Hence (19) was rejected and the endothermic nature of reaction 1 was concluded to be significant. The reaction heat of the cellulose hydrolysis was measured by Kunihisa and Ogawa [12] who reported a slightly endothermic value (ca. $23 \mathrm{~J}$ per $1 \mathrm{~g}$ cellulose). To interpret our much higher $\mathrm{H}_{1}$, we may assume that the initial hydrolysis step is immediately followed by a quick endothermic decomposition of the hydrolysis products. In open pan experiments glucose is not stable above $160^{\circ} \mathrm{C}$ [13]. In the presence of water the decomposition reactions of glucose achieve a significant reaction rate only above $220^{\circ} \mathrm{C}$ [11]. However, no data are available to predict the chemical reactions of a glucose molecule nascent at $240-310^{\circ} \mathrm{C}$. And, as already mentioned, cellulose hydrolysis reactions leading to products other than glucose can also arise above $200^{\circ} \mathrm{C}$ [11].

\section{Evaluation of experiments $B 1-B 7$}

At high sample loading the partial pressure of the product water can reach the saturation point. The calculations have shown that the saturation pressure can be reached in the final section of the evaluated parts of the DSC curves, when the overall $\mathrm{d} q / \mathrm{d} t$ is dominated by reaction 2 . If reaction 2 is a vapor phase process, then it is enough to replace equation (9) by

$\left[\mathrm{H}_{2} \mathrm{O}\right]=\min \left(m_{0} \mathrm{~W} / \mathrm{V},\left[\mathrm{H}_{2} \mathrm{O}\right]_{\mathrm{sat}}\right)$

where $\left[\mathrm{H}_{2} \mathrm{O}\right]_{\text {sat }}$ is the concentration of the saturated water vapor. If reaction 2 is a solid - vapor reaction, the actual water concentration influencing the reaction becomes uncertain and (20) can serve only as a very rough approximation.

Equation (20) was applied in all of the calculations of the paper but had only negligible effects on the evaluation of experiments A1 - A9. (It influenced the evaluation of experiment A9 in a section of about $2{ }^{\circ} \mathrm{C}$ at the very end of the temperature domain evaluated.) In group $\mathbf{B}$, however, the evaluation of six experiments were affected by equation (20). Note that the experimental uncertainty of these experiments was also believed worse than in group A. Keeping these facts in mind, we reduced the goals of the evaluation of experiments B1 - B7 to a single point: can they be described with roughly the same parameters as experiments A1 - A9? To check it, the parameters describing experiments B1 - B7 were forced close to the average parameters of experiments A1 - A9 by a penalty function of type (16). The $\mu$ values for parameters $\log A_{\mathrm{i}}, E_{\mathrm{i}}, Y_{\mathrm{i}}$ and $H_{\mathrm{i}}$ were chosen as $0.01,0.001,0.1$ and 0.001 , respectively. (Higher $\mu$ values resulted in bad fits, lower values led to too high differences.) The results are shown in Table 3 , at the end of this document. Concerning the applicability of assumptions (17) and (18), Table 3 shows the same tendencies as Table 2. At the $Y_{1}=-0.111$, which appears to be the most probable value, the data of the two tables differ by less than $10 \%$. The fit belonging to the $Y_{1}=-0.111$ hypothesis is shown in Figure 2 . 


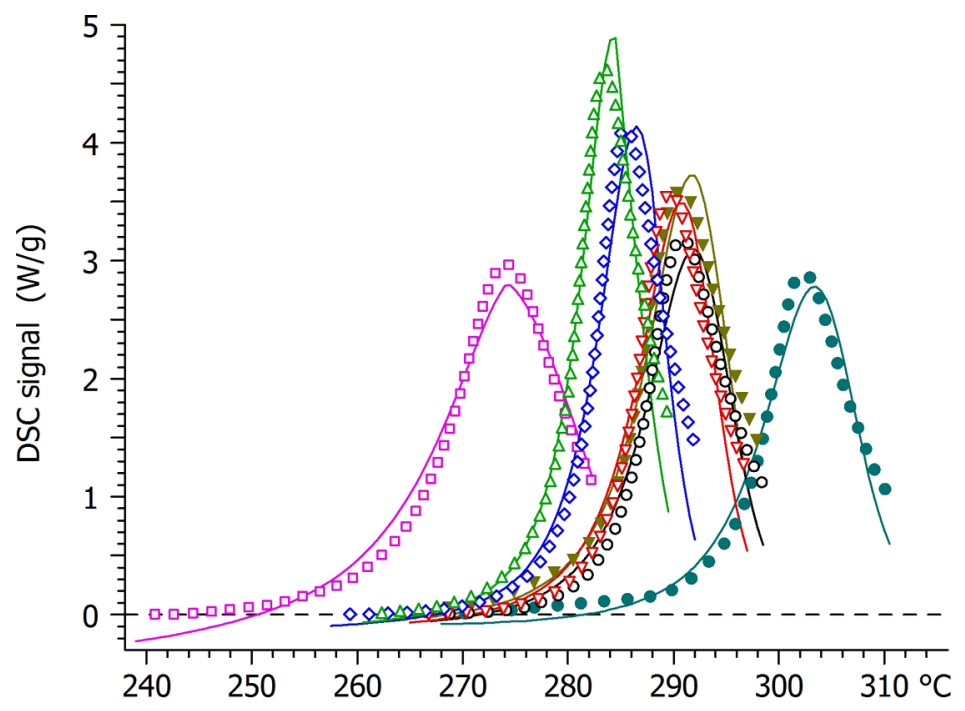

Thermal decomposition of cellulose in sealed sample holders. Experimental (symbols) and simulated (-) DSC curves: - B1 Mass $=4.84 \mathrm{mg}$ Volume $=0.08 \mathrm{~mL} \mathrm{H}_{2} \mathrm{O}$ at $\mathrm{t}=0: 0.34 \mathrm{mg}$ $\checkmark \nabla$ B2 Mass $=4.75 \mathrm{mg}$ Volume $=0.04 \mathrm{~mL} \mathrm{H}_{2} \mathrm{O}$ at $\mathrm{t}=0: 0.34 \mathrm{mg}$ $\circ \circ \circ$ B3 Mass $=13.19 \mathrm{mg}$ Volume $=0.15 \mathrm{~mL} \mathrm{H} \mathrm{H}_{2} \mathrm{O}$ at $\mathrm{t}=0: 0.93 \mathrm{mg}$ $\nabla \nabla \nabla$ B4 Mass $=14.66 \mathrm{mg}$ Volume $=0.15 \mathrm{~mL} \mathrm{H} \mathrm{H}_{2} \mathrm{O}$ at $\mathrm{t}=0: 1.04 \mathrm{mg}$ प $\square$ B5 Mass $=14.21 \mathrm{mg}$ Volume $=0.15 \mathrm{~mL} \mathrm{H} \mathrm{H}_{2} \mathrm{O}$ at $\mathrm{t}=0: 2.73 \mathrm{mg}$ $\diamond \diamond \diamond$ B6 Mass $=18.71 \mathrm{mg}$ Volume $=0.15 \mathrm{~mL} \mathrm{H} \mathrm{H}_{2} \mathrm{O}$ at $\mathrm{t}=0: 1.32 \mathrm{mg}$ $\Delta \triangle \Delta \mathbf{B} 7$ Mass $=22.03 \mathrm{mg}$ Volume $=0.15 \mathrm{~mL} \mathrm{H}_{2} \mathrm{O}$ at $\mathrm{t}=0: 1.56 \mathrm{mg}$

Figure 2: Evaluation of experiments B1 - B7 assuming one mol / monomer unit water uptake in reaction 1 ( $Y_{1}=-$ 0.111). The parameters were forced to be close to the average parameters calculated from experiments A1 - A9. The symbols represent the points of experiments, as marked in the text field. The curves drawn by solid lines are the corresponding calculated $\mathrm{d} q / \mathrm{d} t$ curves. The total $\mathrm{H}_{2} \mathrm{O}$ of the experiments (moisture + added water) is also indicated.

\section{Applicability of the evaluation techniques used in this paper in other areas of thermal analysis}

At present, the use of complex reaction mechanisms in the kinetic evaluation of the thermoanalytical experiments is rare. The situation we discussed under the heading "Evaluation of experiments A1-A9" appears to be a general problem of the field [10]. Relations (14), (15) and (17) show obvious examples of adding supplementary data from chemical knowledge and hypotheses to the information content of the experiments. The method of forcing the parameters of the different experiments close to each other during the evaluation by mathematical techniques may also be useful in other areas of the thermal analysis. At present we do not have other means for the handling of the systematic experimental errors during the simultaneous least squares evaluation of thermoanalytical curves measured at different experimental conditions.

\section{CONCLUSIONS}

Cellulose decomposition enhanced by the presence of water in sealed sample holders was described by mechanism scheme (5). The model resulted in a good fit between the experimental and the calculated data. Nine experiments with varying cellulose mass, moisture, and amount of extra water were described by almost identical parameter sets proving that the same processes take place under the different experimental conditions and the model gives an acceptable description of these processes. The results indicate that the reaction starts with cellulose hydrolysis which may be followed immediately by decomposition reactions to intermediate products. The intermediate products, unable to escape from the hot zone of the sealed 
sample holder, decompose further giving char, water and gases. The model provides a rough approximation at very high sample loading which yield vapor + liquid phase water around $270-300^{\circ} \mathrm{C}$.

\section{ACKNOWLEDGMENT}

This research program was funded by the National Science Foundation (grant INT 8914934), the US Hungarian Science and Technology Joint Fund (grant 22/90), the Hungarian National Research Fund (OTKA, grant 3077/91) and the Coral Industries Endowment. The authors thanks Prof. Tamás Székely and Ms. Bonnie Thompson for their interest in this work.

\section{REFERENCES}

1 M.J.Antal,Jr., W.S.L.Mok, G.Várhegyi and T.Székely, A Review of Methods for Improving the Yield of Charcoal from Biomass Energy Fuels, 4 (1990) 221-225.

2 M.J.Antal,Jr, Patent applied for, 1992

3 A.Broido, M.Weinstein, Low Temperature Isothermal Pyrolysis of Cellulose. In Proc. Third Internat. Conf. Thermal Analysis, vol 3, H.G.Wiedemann (Editor), Birkhäuser Verlag, Basel, 1972

4 A.G.W.Bradbury, Y.Sakai and F.Shafizadeh A Kinetic Model for the Pyrolysis of Cellulose. J. Appl. Polym. Sci., 23 (1979) 3271-3280.

5 G.Várhegyi, M.J.Antal,Jr, T.Székely, F.Till and E.Jakab, Simultaneous Thermogravimetric - Mass Spectrometric Studies on the Thermal Decomposition of Biopolymers. Part 1: Avicel Cellulose in the Presence and Absence of Catalysts. Energ. Fuel., 2 (1988) 267-272.

6 G.Várhegyi, M.J.Antal,Jr, T.Székely and P.Szabó, Kinetics of the Thermal Decomposition of Cellulose, Hemicellulose and Sugar Cane Bagasse. Energ. Fuel., 3 (1989) 329-335.

7 W.S.L.Mok and M.J.Antal,Jr, Effects of Pressure on Biomass Pyrolysis. II. Heat of Reaction of Cellulose Pyrolysis. Thermochmica Acta, 68 (1983) 165-186.

8 M.J.Antal,Jr, H.L.Friedman and F.E.Rogers Kinetics of cellulose Pyrolysis in Nitrogen and Steam. Combust. Sci. Technol., 21 (1980) 141-152.

9 W.S.L.Mok, M.J.Antal,Jr, P.Szabó, G.Várhegyi and B.Zelei Formation of Charcoal from Biomass in a Sealed Reactor, Ind. Eng. Chem. Res., 31 (1992) 1162-1166.

10 Gy.Pokol, G.Várhegyi, Kinetic Aspects of Thermal Analysis. CRC Crit. Rev. Anal. Chem., 19 (1988) 65-93.

11 W.S.L.Mok, M.J.Antal, Jr., and G.Várhegyi, Productive and Parasitic Pathways in Dilute Acid Hydrolysis of Cellulose.

Ind. Eng. Chem. Res., 31 (1992) 94-100.

12 K.S. Kunihisa and H. Ogawa, Acid Hydrolysis of Cellulose in a Differential Scanning Calorimeter. J. Thermal Anal., 30 (1985) 49-59.

13 B.Lóránt, Food Industries. In Differential Thermal Analysis, R.C.Mackenzie (Editor) Academic Press, London, 1972. 
TABLE 2. The average values and standard deviations ${ }^{\mathbf{a}}$ of the parameters resulting from the evaluation of experiments A1 - A9. The parameter sets of the different experiments were forced to be close to each other by constraint (16).

\begin{tabular}{|c|c|c|c|c|c|c|c|c|c|c|}
\hline $\begin{array}{l}\text { Assump- } \\
\text { tion }\end{array}$ & $\begin{array}{l}\text { Fit } \\
{[\%]}\end{array}$ & $\begin{array}{l}\log A_{1} \\
{[\log }\end{array}$ & $\begin{array}{l}\log A_{2} \\
\left.g / L)^{-1}\right]\end{array}$ & $\begin{array}{l}E_{1} \\
{[}\end{array}$ & $\begin{array}{c}E_{2} \\
\text { nol ] }\end{array}$ & $Y_{1}$ & $Y_{2}$ & $\begin{array}{ll}H_{1} & \\
{[} & \mathrm{J} /\end{array}$ & $\begin{array}{c}\mathrm{H}_{2} \\
]\end{array}$ & REMARK \\
\hline$E_{2} \leq 230$ & $\begin{array}{r}2.3 \\
\pm 1.0\end{array}$ & $\begin{array}{r}3.4 \\
\pm 0.1\end{array}$ & $\begin{array}{l}17.2 \\
\pm 0.3\end{array}$ & $\begin{array}{l}71 \\
\pm 1\end{array}$ & $\begin{array}{r}230 \\
\pm 0\end{array}$ & $\begin{array}{l}-0.284 \\
\pm 0.003\end{array}$ & $\begin{array}{r}0.463 \\
\pm 0.001\end{array}$ & $\begin{array}{l}223 \\
\pm 0.1\end{array}$ & $\begin{array}{r}-424 \\
\pm 0.2\end{array}$ & $R e j \in$ \\
\hline $\begin{array}{l}E_{2} \leq 230 \\
Y_{1}=-0.111\end{array}$ & $\begin{array}{r}3.9 \\
\pm 0.7\end{array}$ & $\begin{array}{r}7.0 \\
\pm 0.1\end{array}$ & $\begin{array}{l}16.8 \\
\pm 0.2\end{array}$ & $\begin{array}{r}109 \\
\pm 1\end{array}$ & $\begin{array}{r}228 \\
\pm 2\end{array}$ & $\begin{array}{c}-0.111 \\
-\end{array}$ & $\begin{array}{l}0.379 \\
\pm 0\end{array}$ & $\begin{array}{l}187 \\
\pm 0.3\end{array}$ & $\begin{array}{r}-455 \\
\pm 0.4\end{array}$ & $A C C$ \\
\hline $\begin{array}{l}E_{2} \leq 230 \\
Y_{1}=0\end{array}$ & $\begin{array}{r}4.7 \\
\pm 1.2\end{array}$ & $\begin{array}{r}9.4 \\
\pm 0.1\end{array}$ & $\begin{array}{l}16.7 \\
\pm 0.2\end{array}$ & $\begin{array}{r}135 \\
\pm 1\end{array}$ & $\begin{array}{c}228 \\
\pm 2\end{array}$ & $\begin{array}{c}0.000 \\
-\end{array}$ & $\begin{aligned} & 0.310 \\
\pm & 0\end{aligned}$ & $\begin{array}{l}197 \\
\pm 0.5\end{array}$ & $\begin{array}{l}-520 \\
\quad \pm 0.6\end{array}$ & $R e j \epsilon$ \\
\hline$E_{2} \leq 200$ & $\begin{array}{r}2.4 \\
\pm 1.0\end{array}$ & $\begin{array}{r}4.9 \\
\pm 0.1\end{array}$ & $\begin{array}{l}14.6 \\
\pm 0.3\end{array}$ & $\begin{array}{r}-- \\
87 \\
\pm 1\end{array}$ & $\begin{array}{c}200 \\
\pm 0\end{array}$ & $\begin{array}{l}-0.512 \\
\pm 0.005\end{array}$ & $\begin{array}{r}0.544 \\
\pm 0.001\end{array}$ & $\begin{array}{l}316 \\
\pm 0.2\end{array}$ & $\begin{array}{l}-415 \\
\pm 0.3\end{array}$ & Test $r$ \\
\hline $\begin{array}{l}E_{2} \leq 200 \\
Y_{1}=-0.111\end{array}$ & $\begin{array}{r}4.4 \\
\pm 0.9\end{array}$ & $\begin{array}{r}8.2 \\
\pm 0.1\end{array}$ & $\begin{array}{l}14.1 \\
\pm 0.3\end{array}$ & $\begin{array}{r}121 \\
\pm 1\end{array}$ & $\begin{array}{r}200 \\
\pm 0\end{array}$ & $\begin{array}{c}-0.111 \\
-\end{array}$ & $\begin{array}{l}0.379 \\
\pm 0\end{array}$ & $\begin{array}{l}224 \\
\pm 0.4\end{array}$ & $\begin{array}{l}-482 \\
\quad \pm 0.5\end{array}$ & Test $r$ \\
\hline $\begin{array}{l}------ \\
E_{2} \leq 200 \\
Y_{1}=0\end{array}$ & $\begin{array}{r}5.0 \\
\pm 1.3\end{array}$ & $\begin{array}{l}11.5 \\
\pm 0.1\end{array}$ & $\begin{array}{l}14.1 \\
\pm 0.4\end{array}$ & $\begin{array}{r}157 \\
\pm 1\end{array}$ & $\begin{array}{l}200 \\
\pm 0\end{array}$ & $\begin{array}{c}0.000 \\
-\end{array}$ & $\begin{array}{l}0.310 \\
\pm 0\end{array}$ & $\begin{array}{l}237 \\
\pm 0.8\end{array}$ & $\begin{array}{l}-556 \\
\quad \pm 0.9\end{array}$ & Test \\
\hline
\end{tabular}

${ }^{a}$ Missing standard deviations indicate constant parameters. \pm 0 shows that the corresponding parameter hit the limit of a constraint. 
TABLE 3. The average values and standard deviations ${ }^{\mathbf{a}}$ of the parameters resulting from the evaluation of experiments B1 - B7. The parameters were forced to be close to the average parameters calculated from experiments A1-A9.

\begin{tabular}{|c|c|c|c|c|c|c|c|c|c|c|}
\hline $\begin{array}{l}\text { Assump- } \\
\text { tion }\end{array}$ & $\begin{array}{l}\text { Fit } \\
{\left[\frac{\circ}{0}\right]}\end{array}$ & $\begin{array}{l}\log A_{1} \\
{[\log }\end{array}$ & $\begin{array}{l}\log A_{2} \\
\left.g / L)^{-1}\right]\end{array}$ & $\begin{array}{l}E_{1} \\
{[}\end{array}$ & $\begin{array}{c}E_{2} \\
\text { nol ] }\end{array}$ & $Y_{1}$ & $Y_{2}$ & $\begin{array}{l}H_{1} \\
{[}\end{array}$ & $\mathrm{J} / \mathrm{g}$ & REMARK \\
\hline$E_{2} \leq 230$ & $\begin{array}{r}2.9 \\
\pm 0.8\end{array}$ & $\begin{array}{r}4.3 \\
\pm 1.2\end{array}$ & $\begin{array}{l}17.0 \\
\pm 0.2\end{array}$ & $\begin{array}{r}80 \\
\pm 11\end{array}$ & $\begin{array}{r}230 \\
\pm 0\end{array}$ & $\begin{array}{l}-0.378 \\
\pm 0.123\end{array}$ & $\begin{array}{r}0.469 \\
\pm 0.048\end{array}$ & $\begin{array}{l}211 \\
\pm 12\end{array}$ & $\begin{array}{r}-440 \\
\pm 8\end{array}$ & $R e j \epsilon$ \\
\hline $\begin{array}{l}E_{2} \leq 230 \\
Y_{1}=-0.111\end{array}$ & $\begin{array}{r}5.5 \\
\pm 0.6\end{array}$ & $\begin{array}{r}6.4 \\
\pm 0.4\end{array}$ & $\begin{array}{l}16.4 \\
\pm 0.3\end{array}$ & $\begin{array}{r}101 \\
\pm 4\end{array}$ & $\begin{array}{r}229 \\
\pm 2\end{array}$ & $\begin{array}{c}-0.111 \\
-\end{array}$ & $\begin{array}{l}0.379 \\
\pm 0\end{array}$ & $\begin{array}{l}173 \\
\pm 10\end{array}$ & $\begin{array}{r}-493 \\
\pm 19\end{array}$ & $A \subset C \theta$ \\
\hline $\begin{array}{l}E_{2} \leq 230 \\
Y_{1}=0\end{array}$ & $\begin{array}{r}5.9 \\
\pm 0.4\end{array}$ & $\begin{array}{l}11.7 \\
\pm 1.6\end{array}$ & $\begin{array}{l}16.3 \\
\pm 0.2\end{array}$ & $\begin{array}{l}158 \\
\pm 16\end{array}$ & $\begin{array}{c}230 \\
\pm 0\end{array}$ & $\begin{array}{c}0.000 \\
-\end{array}$ & $\begin{array}{l}0.310 \\
\pm 0\end{array}$ & $\begin{array}{l}170 \\
\pm 20\end{array}$ & $\begin{array}{r}-576 \\
\pm 40\end{array}$ & Rejected \\
\hline$E_{2} \leq 200$ & $\begin{array}{r}4.1 \\
\pm 0.9\end{array}$ & $\begin{array}{r}5.5 \\
\pm 0.6\end{array}$ & $\begin{array}{l}14.2 \\
\pm 0.4\end{array}$ & $\begin{array}{l}92 \\
\pm 6\end{array}$ & $\begin{array}{r}200 \\
\pm 0\end{array}$ & $\begin{array}{l}-0.511 \\
\pm 0.277\end{array}$ & $\begin{array}{r}0.528 \\
\pm 0.100\end{array}$ & $\begin{array}{r}293 \\
\pm 28\end{array}$ & $\begin{array}{r}-433 \\
\pm 14\end{array}$ & Test \\
\hline $\begin{array}{l}E_{2} \leq 200 \\
Y_{1}=-0.111\end{array}$ & $\begin{array}{r}5.6 \\
\pm 0.7\end{array}$ & $\begin{array}{r}7.7 \\
\pm 0.8\end{array}$ & $\begin{array}{l}13.6 \\
\pm 0.1\end{array}$ & $\begin{array}{r}115 \\
\pm 7\end{array}$ & $\begin{array}{r}200 \\
\pm 0\end{array}$ & $\begin{array}{c}-0.111 \\
-\end{array}$ & $\begin{array}{l}0.379 \\
\pm 0\end{array}$ & $\begin{array}{l}208 \\
\pm 14\end{array}$ & $\begin{array}{r}-517 \\
\pm 25\end{array}$ & Test run \\
\hline $\begin{array}{l}E_{2} \leq 200 \\
Y_{1}=0\end{array}$ & $\begin{array}{r}5.9 \\
\pm 0.3\end{array}$ & $\begin{array}{l}13.6 \\
\pm 1.5\end{array}$ & $\begin{array}{l}13.5 \\
\pm 0.2\end{array}$ & $\begin{array}{l}178 \\
\pm 15\end{array}$ & $\begin{array}{r}200 \\
\pm 0\end{array}$ & $\begin{array}{c}0.000 \\
-\end{array}$ & $\begin{array}{l}0.310 \\
\pm 0\end{array}$ & $\begin{array}{l}205 \\
\pm 20\end{array}$ & $\begin{array}{r}-611 \\
\pm 39\end{array}$ & Test $r$ \\
\hline
\end{tabular}

${ }^{a}$ Missing standard deviations indicate constant parameters. \pm 0 shows that the corresponding parameter hit the limit of a constraint. 